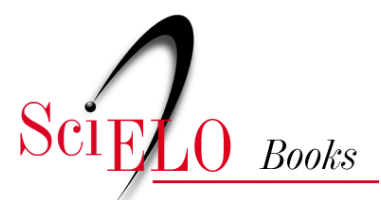

\title{
3. O Juramento de Hipócrates
}

\author{
Joffre Marcondes de Rezende
}

\section{SciELO Books / SciELO Livros / SciELO Libros}

REZENDE, J. M. O Juramento de Hipócrates. In: À sombra do plátano: crônicas de história da medicina [online]. São Paulo: Editora Unifesp, 2009, pp. 31-48. História da Medicina series, vol. 2. ISBN 978-85-61673-63-5. https://doi.org/10.7476/9788561673635.0004.

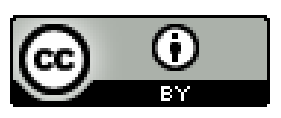

All the contents of this work, except where otherwise noted, is licensed under a Creative Commons Attribution 4.0 International license.

Todo o conteúdo deste trabalho, exceto quando houver ressalva, é publicado sob a licença Creative Commons Atribição 4.0.

Todo el contenido de esta obra, excepto donde se indique lo contrario, está bajo licencia de la licencia Creative Commons Reconocimento 4.0. 


\section{O Juramento de Hipócrates*}

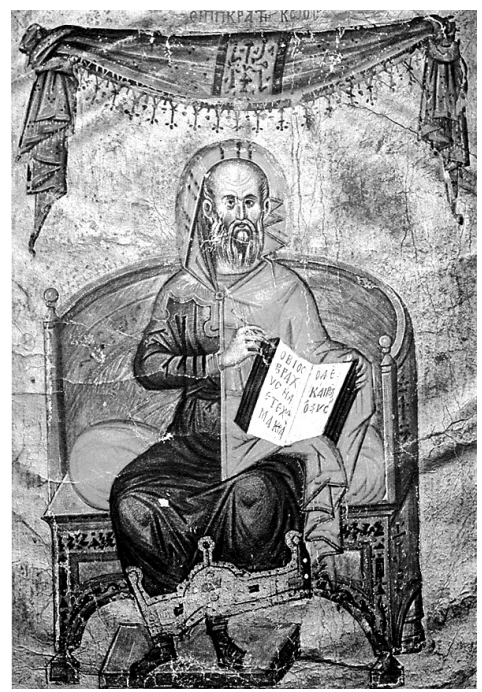

Hipócrates, visto por um artista bizantino, c. I342.

$\mathrm{E}$

m uma pequena ilha do mar Egeu, na Grécia, próximo ao litoral da Ásia Menor - a ilha de Cós - floresceu no século v a.C. uma escola médica destinada a mudar os rumos da medicina, sob a inspiração de um personagem que se tornaria, desde então, o paradigma de todos os médicos: Hipócrates.

A escola hipocrática separou a medicina da religião e da magia, afastou as crenças em causas sobrenaturais das doenças e fundou os alicerces da medicina racional e científica. Ao lado disso, deu um sentido de dignidade à profissão médica, estabelecendo as normas éticas de conduta que devem nortear a vida do médico, tanto no exercício profissional, como fora dele.

Na coleção de 72 livros contemporâneos da escola hipocrática, conhecida como Corpus Hippocraticum, há sete livros que tratam exclusivamente da ética médica. São eles: Juramento, Da Lei, Da Arte, Da Antiga

* Reproduzido da Revista Paraense de Medicina, vol. I7 (I), pp. 38-47, 2003. 
Medicina, Da Conduta Honrada, Dos Preceitos, Do Médico (Castiglioni, I93 I, p. I3I).

Sobressai dentre eles o Juramento, a ser proferido por todos aqueles considerados aptos a exercer a medicina, no momento em que são aceitos como tal por seus pares e admitidos como novos membros da classe médica. O juramento hipocrático é considerado um patrimônio da humanidade por seu elevado sentido moral e, durante séculos, tem sido repetido como um compromisso solene dos médicos, ao ingressarem na profissão.

\section{Textos Manuscritos Preservados}

O texto do juramento de Hipócrates que hoje se encontra em vários idiomas resultou de traduções oriundas de antigos e raros manuscritos. Embora sem comprovação, aceita-se que os citados manuscritos reproduzem o texto original de quando o mesmo foi escrito. Os mais antigos manuscritos conhecidos, segundo Bernardes de Oliveira, são:

I. O manuscrito Urbinas Graecus 64 da Biblioteca Apostólica Vaticana. Está localizado entre os séculos X e XI. Suas palavras iniciais esclarecem: “Texto do Juramento Hipocrático que pode ser jurado pelos cristãos”. O interessante documento é escrito em forma de cruz para bem marcar o patrocínio religioso. Inicia-se com a saudação laudatória habitual: "Bendito seja Deus, o Pai de Nossso Senhor Jesus Cristo; para sempre bendito seja...”. Sua redação acompanha o texto clássico com algumas variantes e alterações das quais a principal é a omissão da cláusula referente à operação da calculose vesical.

2. O segundo, por ordem de antiguidade, é o manuscrito Marcianus Venetus $Z$ 269, do século XI, pertencente à Biblioteca de S. Marcos de Veneza. O juramento aí se acha como sendo o texto original. Inicia-se com a invocação dos deuses da mitologia grega, consoante sua origem pagã.

3. Manuscrito do século XII da Biblioteca Apostólica Vaticana: Vaticanus Graecus 276, fólio I recto.

4. Manuscrito do século XII da Biblioteca Nacional de Paris (Bernardes de Oliveira, I974, pp. 32I-338).

O último manuscrito citado encerra a versão pagã, com a invocação inicial dos deuses da mitologia grega e corresponde ao texto mais difundido atualmente. 
Os demais manuscritos conhecidos do juramento de Hipócrates são todos dos séculos XIV e Xv. Embora sejam equivalentes, verificam-se mínimas diferenças de redação.

Há atualmente na ilha de Cós uma fundação, a Fundação Hipocrática Internacional de Cós, que é, ao mesmo tempo, museu e centro de pesquisas sobre a medicina hipocrática. Nesta fundação, preserva-se um texto idêntico ao que se encontra no livro Ancient Medicine, de Edelstein, que, por sua vez, o transcreveu da obra Corpus Medicorum Graecorum, editada em Berlim por Heiberg, em I927 (Edelstein, I987, p. 5).

\section{Traduções do Texto Original}

A partir dos manuscritos já referidos, foram feitas traduções do juramento de Hipócrates em latim, hebraico, árabe e nos demais idiomas.

Duas traduções em inglês e duas em francês tornaram-se clássicas e têm servido de referência para as versões em outros idiomas.

As versões clássicas em inglês são a de Francis Adams, de I 849, transcrita na coleção Harvard Classic, vol. 38, de I9ıо, e a de W. H. S. Jones, que se encontra na coleção Loeb Classical Library, desde I923 (Adams, I9Io; Jones, I972, pp. 298-30I). As versões em francês são a de Littré, de I844, e a de Daremberg, de I 855 (Littré, I932, p. 3; Daremberg, I969, pp. I I2-I I3).

Transcrevemos a seguir a tradução de Adams, em inglês, e a de Littré, em francês.

\section{The oath by Hippocrates}

I swear by Apollo the physician, and Aesculapius, and Health, and All-heal, and all the gods and goddesses, that, according to my ability and judgment, I will keep this Oath and this stipulation - to reckon him who taught me this Art equally dear to me as my parents, to share my substance with him, and relieve his necessities if required; to look upon his offspring in the same footing as my own brothers, and to teach them this art, if they shall wish to learn it, without fee or stipulation; and that by precept, lecture, and every other mode of instruction, I will impart a knowledge of the Art to my own sons, and those of my teachers, and to disciples bound by a stipulation and oath according to the law of medicine, but to none others. I will follow that system of regimen which, according to my ability and 
OPKO乏

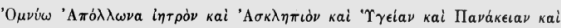

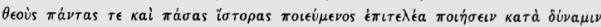

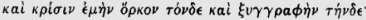

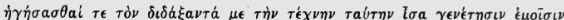

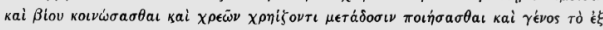

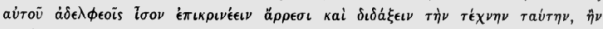

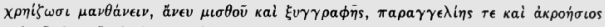

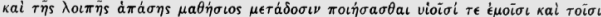

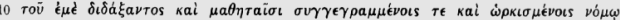

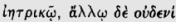

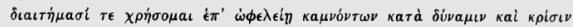

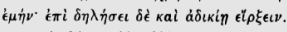

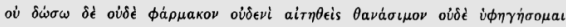

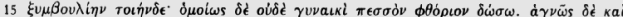

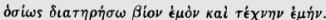

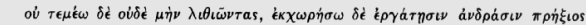
$\tau \tilde{\eta} \sigma \delta \epsilon$.

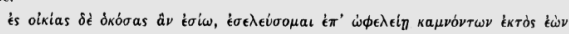

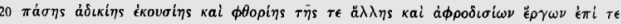

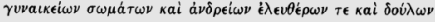

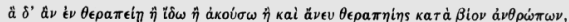

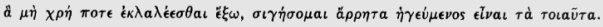

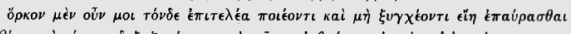

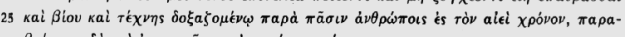

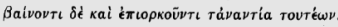

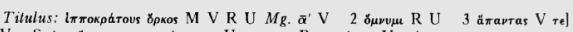

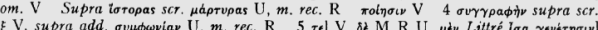

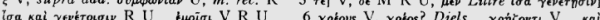

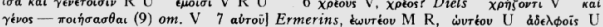

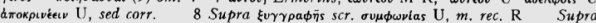

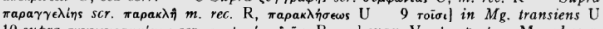

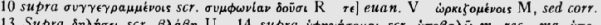

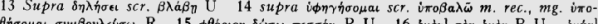
Thopal fup

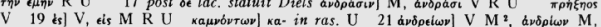
àsóiwy R U 22 pr.

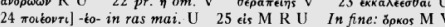

*Text and Apparatus Criticus are taken from Hippocratis Opera, ed. I. 1

Heiberg, Corpus Medicorum Graecorum 1, 1, 1927, pp. 4-5.

Reprodução do livro de Edelstein, Ancient Medicine.

judgment, I consider for the benefit of my patients, and abstain from whatever is deleterious and mischievous. I will give no deadly medicine to any one if asked, nor suggest any such counsel; and in like manner I will not give to a woman a pessary to produce abortion. With purity and with holiness I will pass my life and practice my Art. I will not cut persons laboring under the stone, but will leave this to be done by men who are practitioners of this work. Into whatever houses I enter, I will go into them for the benefit of the sick, and will abstain from every voluntary act of mischief and corruption; and, further from the seduction of females or males, of freemen and slaves. Whatever, in connection with my professional practice or not, in connection with it, I see or hear, in the life of men, which ought not to be spoken of abroad, I will not divulge, as reckoning that all such should be kept secret. While I continue to keep this Oath unviolated, may it be granted to me to enjoy life and the practice of the art, respected by all men, in all times! But should I trespass and violate this Oath, may the reverse be my lot. 


\section{Serment d'Hippocrate}

Je jure, par Apollon, médecin, par Esculape, par Hygie et Panacée, par tous les dieux et toutes les déesses, les prenant à témoin, que je remplirai, suivant mes forces et ma capacité, le serment et l'engagement suivants: je mettrai mon maître de médecine au même rang que les auteurs de mes jours, je partagerai avec lui mon avoir, et, le cas échéant, je pourvoirai à ses besoins; je tiendrai ses enfants pour des frères, et, s'ils désirent apprendre la médecine, je la leur enseignerai sans salaire ni engagement. Je ferai part des préceptes, des leçons orales et du reste de l'enseignement à mes fils, à ceux de mon maître, et aux disciples liés par un engagement et un serment suivant la loi médicale, mais à nul autre. Je dirigerai le régime des malades à leur avantage, suivant mes forces et mon jugement, et je m'abstiendrai de tout mal et injustice. Je ne remettrai à personne du poison, si on m'en demande, ni ne prendrai l'initiative d'une pareille suggestion; semblablement, je ne remettrai à aucune femme un pessaire abortif. Je passerai ma vie et j'exercerai mon art dans l'innocence et la pureté. Je ne pratiquerai pas l'opération de la taille, je la laisserai aux gens qui s'en occupent. Dans quelque maison que j'entre, j'y entrerai pour l'utilité des malades, me préservant de tout méfait volontaire et corrupteur, et surtout de la séduction des femmes et des garçons, libres ou esclaves. Quoi que je voie ou entende dans la société pendant l'exercice ou même hors de l'exercice de ma profession, je tairai ce qui n'a jamais besoin d'être divulgué, regardant la discrétion comme un devoir en pareil cas. Si je remplis ce serment sans l'enfreindre, qu'il me soit donné de jouir heureusement de la vie et de ma profession, honoré à jamais parmi les hommes; si je le viole et que je me parjure, puissè-je avoir un sort contraire!

Em português há várias traduções, a maioria baseada nos textos clássicos em inglês ou francês, e outras feitas diretamente do texto grego, hoje facilmente acessível em reproduções impressas.

Transcrevemos a tradução em português de Bernardes de Oliveira, autor do livro A Evolução da Medicina até o Início do Século xx, baseada no texto inglês de Jones (Bernardes de Oliveira, I98 I, p. 79):

\section{Juramento de Hipócrates}

Juro por Apolo Médico, por Esculápio, por Higeia, por Panaceia e por todos os deuses e deusas, tomando-os como testemunhas, obedecer, de acordo com meus conhecimentos e meu critério, este juramento: Considerar meu mestre nesta arte 
igual aos meus pais, fazê-lo participar dos meios de subsistência que dispuser, e, quando necessitado com ele dividir os meus recursos; considerar seus descendentes iguais aos meus irmãos; ensinar-lhes esta arte se desejarem aprender, sem honorários nem contratos; transmitir preceitos, instruções orais e todos outros ensinamentos aos meus filhos, aos filhos do meu mestre e aos discípulos que se comprometerem e jurarem obedecer a Lei dos Médicos, porém, a mais ninguém. Aplicar os tratamentos para ajudar os doentes conforme minha habilidade e minha capacidade, e jamais usá-los para causar dano ou malefício. Não dar veneno a ninguém, embora solicitado a assim fazer, nem aconselhar tal procedimento. Da mesma maneira não aplicar pessário em mulher para provocar aborto. Em pureza e santidade guardar minha vida e minha arte. Não usar da faca nos doentes com cálculos, mas ceder o lugar aos nisso habilitados. Nas casas em que ingressar apenas socorrer o doente, resguardando-me de fazer qualquer mal intencional, especialmente ato sexual com mulher ou homem, escravo ou livre. Não relatar o que no exercício do meu mister ou fora dele no convívio social eu veja ou ouça e que não deva ser divulgado, mas considerar tais coisas como segredos sagrados. Então, se eu mantiver este juramento e não o quebrar, possa desfrutar honrarias na minha vida e na minha arte, entre todos os homens e por todo o tempo; porém, se transigir e cair em perjúrio, aconteça-me o contrário.

Em todos os idiomas, as traduções oferecidas diferem entre si em alguns aspectos relativos à linguagem empregada, embora mantenham todas o núcleo central dos preceitos que compõem o juramento.

Analisando-se o teor de várias traduções, verificamos que as diferenças existentes entre elas se encontram principalmente em algumas passagens e no significado de determinadas palavras gregas, que não encontram equivalentes em outros idiomas ou, o que é mais comum, na sua polissemia, que permite um leque de opções na língua de chegada.

Selecionamos dez das mais acreditadas versões em português, sendo oito do Brasil e duas de Portugal, para um estudo comparativo de como aquelas palavras foram traduzidas. As versões utilizadas foram as seguintes:

- Brasil: Flamínio Fávaro, Livro de Medicina Legal; Ivolino de Vasconcelos, Instituto Brasileiro de História da Medicina; a tradução de René Laclete para a História da Medicina, de Arturo Castiglioni; Bernardes de Oliveira, A Evolução da Medicina até o Início do Século xx; Otacílio Carvalho 
Lopes, A Medicina no Tempo; Alexandre Correa, Revista Paulista de Medicina (abr. 1974); Conselho Regional de Medicina do Estado de São Paulo (Cremesp); Universidade de Ribeirão Preto (Unaerp).

- Portugal: tradução baseada em Edelstein e F. Guerra; tradução baseada em Littré.

O primeiro exemplo encontramos nas palavras dynamin kaí krísin, expressão empregada em duas passagens, uma no primeiro parágrafo e outra no terceiro parágrafo do texto original em grego.

No primeiro parágrafo:

\begin{tabular}{c|c} 
Expressão utilizada & Número de traduções \\
\hline poder e razão & 3 \\
habilidade e julgamento & 2 \\
poder de discernimento & $\mathrm{I}$ \\
conhecimento e critério & $\mathrm{I}$ \\
força e aptidão & $\mathrm{I}$ \\
força e inteligência & $\mathrm{I}$ \\
capacidade e discernimento & $\mathrm{I}$
\end{tabular}

No terceiro parágrafo:

\begin{tabular}{c|c} 
Expressão utilizada & Número de traduções \\
\hline habilidade e julgamento & 2 \\
saber e razão & 2 \\
autoridade e discernimento & $\mathrm{I}$ \\
habilidade e capacidade & $\mathrm{I}$ \\
força e juízo & $\mathrm{I}$ \\
poder e entendimento & $\mathrm{I}$ \\
força e inteligência & $\mathrm{I}$ \\
melhor parecer & $\mathrm{I}$
\end{tabular}

O segundo exemplo temos na expressão diaitémasi te khrésomai, que abre o terceiro parágrafo. Diaite, em grego, tanto significa "dieta" como "regime de vida". 


\begin{tabular}{c|c} 
Expressão utilizada & Número de traduções \\
\hline Aplicarei os regimes & 3 \\
Seguirei aqueles regimes & 2 \\
Adotarei o regime & I \\
Prescreverei o regime & I \\
Prescreverei o regime dietético & I \\
Ordenarei a dieta & I \\
Aplicarei os tratamentos & I
\end{tabular}

Outro exemplo está na expressão phármakon... thanásimon, encontrada no quarto parágrafo. Phármakon, em grego, expressa qualquer substância capaz de atuar no organismo, seja no sentido benéfico ou maléfico, ou seja como remédio ou como veneno. Nas dez versões em português deparamos com as seguintes traduções:

\begin{tabular}{c|c} 
Expressão utilizada & Número de traduções \\
\hline remédio mortal & 4 \\
venenos mortais & 2 \\
venenos & 2 \\
medicamento mortal & I \\
droga mortal & I
\end{tabular}

A crítica que se pode fazer neste passo diz respeito à expressão "remédio mortal" ou "medicamento mortal". É uma incongruência a denominação de remédio ou medicamento mortal. Se é reconhecidamente mortal, deixa de ser remédio ou medicamento e passa a ser veneno.

A proibição da prática do aborto no texto original refere-se ao uso de pessário, naturalmente o recurso existente na época de Hipócrates, que poderia ser empregado pelos médicos. Nas versões modernas, a tradução por vezes foge ao original, com a intenção de abranger outros métodos abortivos atualmente disponíveis. 


\begin{tabular}{c|c} 
Expressão utilizada & Número de traduções \\
\hline pessário abortivo & 6 \\
medicação abortiva & I \\
remédio abortivo & I \\
substância abortiva & I \\
(sem referência) & I
\end{tabular}

Outra passagem que apresenta diferenças marcantes nas várias versões é a do antepenúltimo parágrafo, onde se lê no original grego: aphrodision érgon epi te gynaikeion somáton kaí andreion... Nas dez versões em português foram usadas as seguintes traduções:

\begin{tabular}{c|c} 
Expressão utilizada & Número de traduções \\
\hline sedução de mulheres e de homens & 2 \\
prazeres do amor com mulheres ou com homens & 2 \\
sedução de mulheres e homens & $\mathrm{I}$ \\
sedução de mulheres e de rapazes & $\mathrm{I}$ \\
sedução, sobretudo os prazeres do amor & $\mathrm{I}$ \\
contatos sexuais com mulheres e homens & $\mathrm{I}$ \\
comércio voluptuoso, seja com mulher ou homem & $\mathrm{I}$ \\
ato sexual & $\mathrm{I}$
\end{tabular}

Vemos que todas as versões citadas afastaram-se da tradução literal. A expressão aphrodision érgon tem o sentido de "ato erótico", e gynaikeion somáton kaí andreion, "corpo de mulher e de homem". A tradução mais próxima do texto seria "ato libidinoso em corpo de mulher ou de homem". $\mathrm{O}$ ato libidinoso difere de "sedução" e de "prazeres do amor" e nem sempre culmina com o "ato sexual". Pode ser praticado com ou sem participação da outra pessoa.

Das traduções citadas, a que mais se aproxima do texto original é "comércio voluptuoso, seja com mulher ou homem". "Comércio", no entanto, subentende o concurso de ambas as partes, enquanto "ato" pode ser unilateral. Em traduções francesas, usa-se a expressão entreprise voluptuese. Em uma versão em espanhol, o tradutor se refere tão somente à "seducción de las mujeres jóvenes, libres o esclavas". 
No penúltimo parágrafo, a expressão bíon anthrópon foi traduzida do seguinte modo:

\begin{tabular}{c|c} 
Expressão utilizada & Número de traduções \\
\hline vida dos homens & 3 \\
comércio da vida & 2 \\
vida do homem & I \\
convívio social & I \\
convívio da sociedade & I \\
(sem referência) & 2
\end{tabular}

Estas dificuldades e variações de tradução são comuns a todos os idiomas. O importante é que o tradutor consiga transmitir a ideia contida no texto original de forma expressiva e com a máxima exatidão. $\mathrm{O}$ juramento é simbólico e impregnado de sacralidade, qualquer que seja a sua tradução. O importante é o compromisso que o recém-formado assume perante sua própria consciência e a sociedade de cumprir os preceitos éticos contidos no juramento.

\section{Formas Resumidas do Juramento}

Textos abreviados do juramento têm sido utilizados em diferentes países e idiomas, tendo em vista a extensão do texto original para leitura durante uma solenidade festiva como a da conclusão do curso médico.

$\mathrm{Na}$ França, é corrente um modelo abreviado conhecido como juramento de Montpellier, certamente oriundo de uma das mais antigas e celebradas escolas médicas da França - a de Montpellier. O texto original em francês deste juramento tem a seguinte redação:

En présence des maîtres de cette école et de mes condisciples, je promets et je jure d'être fidèle aux lois de l'Honneur et de la Probité dans l'exercice de la Médecine.

Je donnerai mes soins à l'indigent et n'exigerai jamais un salaire au-dessus de mon travail. Admis dans l'intérieur des maisons, mes yeux ne verront pas ce qui s'y passe, ma langue taira les secrets qui me seront confiés et mon état ne servira ni à corrompre les moeurs, ni à favoriser le crime. 
Reconnaissant envers mes maîtres, je tiendrai leurs enfants et ceux de mes confrères pour des frères, et s'ils devaient apprendre la Médecine ou recourir à mes soins, je les instruirais ou les soignerais sans salaire ni engagement.

Si je remplis ce serment sans l'enfreindre, qu'il me soit donné de jouir heureusement de ma vie et de ma profession, honoré à jamais parmi les hommes; si je le viole et que je me parjure, puissé-je avoir un sort contraire.

Posteriormente surgiu um modelo ainda mais sintético com o seguinte texto (Carpenter e Mangin-Lazarus, I996, pp. 37-39):

En présence des Maîtres de cette Faculté, de mes chers condisciples et selon la tradition d'Hippocrate, je promets et je jure d'être fidèle aux lois de l'honneur et de la probité dans l'exercice de la Médecine.

Je donnerai mes soins gratuits à l'indigent, et n'exigerai jamais un salaire au dessus de mon travail. Admis dans l'intérieur des maisons, mes yeux ne verront pas ce qui s'y passe, ma langue taira les secrets qui me seront confiés et mon état ne servira pas à corrompre les moeurs ni à favoriser le crime. Respectueux et reconnaissant envers mes Maîtres, je rendrai à leurs enfants l'instruction que j'ai reçue de leurs pères.

Que les hommes m'accordent leur estime si je suis fidèle à mes promesses. Que je sois couverte d'opprobre et méprisé de mes confrères si j’y manque.

Observamos que no modelo de Montpellier, um novo compromisso foi introduzido: o de atender gratuitamente os pobres e o de ser moderado na cobrança dos honorários. Por sua vez, outros preceitos enumerados no texto original não foram mencionados, ficando subentendidos nas expressões genéricas de "ser fiel às leis da honra e da probidade no exercício da medicina" e de "não corromper os costumes, nem favorecer o crime".

$\mathrm{Na}$ língua inglesa também se encontram formas abreviadas do juramento que não seguem exatamente a mesma linha do modelo francês. Vamos citar, como exemplo, o texto usado no New York Medical College:

I do solemnly swear by whatever I hold most sacred, that I will be loyal to the profession of medicine and just and generous to its members.

That I will lead my life and practice my Art in uprightness and honor. 
That into whatsoever home I shall enter it shall be for the good of the sick and the well to the utmost of my power and that I will hold myself aloof from wrong and from corruption and from the tempting of others to vice.

That I will exercise my Art, solely for the cure of my patients and the prevention of disease and will give no drugs and perform no operation for a criminal purpose and far less suggest such a thing.

That whatsoever I shall see or hear of the lives of men and women which is not fitting to be spoken, I will keep inviolably secret.

These things I do promise and in proportion as I am faithful to this oath, may happiness and good repute be ever mine, the opposite if I shall be foresworn.

No Brasil, a maioria das faculdades utilizam um modelo simplificado, tradução de um texto latino que, segundo o prof. Edmundo Vasconcelos, chegou a ser usado na Faculdade de Medicina da Universidade de São Paulo. A tradução vernácula desse texto é do seguinte teor (Vasconcelos, I974):

Prometo que ao exercer a arte de curar, mostrar-me-ei sempre fiel aos preceitos da honestidade, da caridade e da ciência.

Penetrando no interior dos lares, meus olhos serão cegos, minha língua calará os segredos que me forem revelados, o que terei como preceito de honra.

Nunca me servirei da profissão para corromper os costumes ou favorecer o crime.

Se eu cumprir este juramento com fidelidade, goze eu, para sempre, a minha vida e a minha arte, com boa reputação entre os homens.

Se o infringir ou dele afastar-me, suceda-me o contrário.

Uma variante desse texto tem livre curso em nossas faculdades e é encontrado nos convites de formatura. Difere do primeiro em um pequeno detalhe de redação, que, entretanto, modifica inteiramente o sentido da frase. Está assim redigido:

Prometo que ao exercer a arte de curar, mostrar-me-ei sempre fiel aos preceitos da honestidade, da caridade e da ciência.

Penetrando no interior dos lares, meus olhos serão cegos, minha língua calará os segredos que me forem revelados, os quais terei como preceito de honra. 
Nunca me servirei da profissão para corromper os costumes ou favorecer o crime. Se eu cumprir este juramento com fidelidade, goze eu, para sempre, a minha vida e a minha arte, com boa reputação entre os homens.

Se o infringir ou dele afastar-me, suceda-me o contrário.

Comparando-se as duas versões, vê-se que a única diferença consiste na substituição, no segundo parágrafo, da locução pronominal "o que" pela locução "os quais".

Na primeira versão, “o que” refere-se ao enunciado na frase anterior, ou seja, expressa a intenção do médico de guardar sigilo em relação aos "segredos que me forem revelados". Na segunda versão, a locução pronominal "os quais", no plural, tem como antecedente "os segredos que me forem revelados". Ora, não faz o menor sentido fazer "dos segredos que me forem revelados" "preceito de honra". É fora de dúvida que esta construção está gramaticalmente incorreta e deve ser abandonada em favor da primeira.

\section{O Juramento de Hipócrates nas Escolas Médicas Brasileiras}

No sentido de verificar como se situa na atualidade o juramento de Hipócrates em nosso país, realizamos uma pesquisa junto às escolas médicas brasileiras, solicitando que nos fornecessem o texto utilizado na solenidade de formatura do curso médico. Enviamos uma carta-circular, em nome da Sociedade Brasileira de História da Medicina, a 82 faculdades e recebemos resposta de 4 I. Destas, três não especificaram o texto em uso, razão pela qual serão incluídas nesta análise somente 38 faculdades.

$\mathrm{O}$ resultado desta pesquisa evidenciou que apenas três das 38 usam o juramento por extenso em sua forma original e que a maioria utiliza o modelo simplificado de uso corrente, conforme o quadro abaixo:

\begin{tabular}{c|c|c} 
Modalidades de texto em uso & Faculdades & $\%$ \\
\hline Texto simplificado & 23 & 60,5 \\
Mais de um texto & 6 & $\mathrm{I} 5,8$ \\
Texto por extenso & 3 & 7,9 \\
Textos próprios & 3 & 7,9 \\
Texto por extenso, modificado & 2 & 5,3 \\
Declaração de Genebra & $\mathrm{I}$ & 2,6
\end{tabular}


Das seis faculdades que utilizam mais de um texto, cinco incluem a forma simplificada, que é, assim, adotada em 28 faculdades $(73,7 \%)$. Destas, apenas nove $(32, \mathrm{I} \%)$ usam a redação correta com a locução pronominal "o que", enquanto dezoito $(64,3 \%)$ empregam a locução pronominal "os quais" e uma $(3,6 \%)$, “aos quais".

\section{“Atualização" do Juramento de Hipócrates}

No século xx, o progresso científico e o avanço tecnológico da medicina, aliados à evolução do pensamento e dos costumes, trouxeram novos conceitos e novos aspectos relativos à ética médica, e a validade do juramento de Hipócrates passou a ser questionada, se não em seu significado simbólico, pelo menos em seu conteúdo. Surgiram, então, numerosas propostas no sentido de "atualizar" ou "modernizar" o texto do juramento. Essa tendência se acentuou nos últimos anos.

As alterações sugeridas visam, principalmente, a compatibilizá-lo com a bioética e adaptá-lo à problemática decorrente da prática médica atual, com o objetivo de evitar a conivência dos médicos com as falhas dos atuais sistemas de saúde, sempre que houver prejuízo para os doentes, e com os interesses financeiros da indústria farmacêutica e de equipamentos médicos, que procuram influenciar a conduta do médico.

As modificações introduzidas contemplam a autonomia do paciente; justiça social e mercantilização da medicina; afrouxam as obrigações dos discípulos para com seus mestres; substituem a proibição por regulamentação do aborto; e suprimem o item referente à operação de calculose vesical.

Deixando de lado as inúmeras propostas de caráter pessoal, listamos apenas aquelas oriundas de entidades de maior representatividade. As principais foram:

I. Declaração de Genebra da Associação Médica Mundial (I948)

2. Texto de Brighton, Estados Unidos (I995)

3. Código de Deontologia Médica da França (I995)

4. British Medical Association (I997)

5. Carta do Profissionalismo Médico (2002)

A Declaração de Genebra, a mais antiga e conhecida de todas, tem sido utilizada em vários países na solenidade de recepção aos novos médicos 
inscritos na respectiva Ordem ou Conselho de Medicina. A versão clássica em língua portuguesa tem a seguinte redação:

$\mathrm{Eu}$, solenemente, juro consagrar minha vida a serviço da Humanidade.

Darei como reconhecimento a meus mestres, meu respeito e minha gratidão.

Praticarei a minha profissão com consciência e dignidade.

A saúde dos meus pacientes será a minha primeira preocupação.

Respeitarei os segredos a mim confiados.

Manterei, a todo custo, no máximo possível, a honra e a tradição da profissão médica.

Meus colegas serão meus irmãos.

Não permitirei que concepções religiosas, nacionais, raciais, partidárias ou sociais intervenham entre meu dever e meus pacientes.

Manterei o mais alto respeito pela vida humana, desde sua concepção. Mesmo sob ameaça, não usarei meu conhecimento médico em princípios contrários às leis da natureza.

Faço estas promessas, solene e livremente, pela minha própria honra.

Em 1994, a Assembleia Geral da Associação Médica Mundial modificou ligeiramente o texto. Sua versão em português ficou com a seguinte redação:

No momento de me tornar um profissional médico:

Prometo solenemente dedicar a minha vida a serviço da Humanidade.

Darei aos meus mestres o respeito e o reconhecimento que lhes são devidos.

Exercerei a minha arte com consciência e dignidade.

A saúde do meu paciente será minha primeira preocupação.

Mesmo após a morte do paciente, respeitarei os segredos que a mim foram confiados.

Manterei, por todos os meios ao meu alcance, a honra da profissão médica.

Os meus colegas serão meus irmãos.

Não deixarei de exercer meu dever de tratar o paciente em função de idade, doença, deficiência, crença religiosa, origem étnica, sexo, nacionalidade, filiação político-partidária, raça, orientação sexual, condições sociais ou econômicas. 
Terei respeito absoluto pela vida humana e jamais farei uso dos meus conhecimentos médicos contra as leis da Humanidade.

Faço essas promessas solenemente, livremente e sob a minha honra.

O texto de Brighton foi elaborado por um grupo de 35 eticistas, médicos e não médicos, reunidos em Brighton, Estados Unidos, em I995 (Value of Life Committee Inc., s.d.).

O texto do Código de Deontologia Médica da França foi estabelecido em lei pelo decreto n. 95-I000, artigo ıo9, de 6 de setembro de I995 (Ordre National des Médecins, s.d.).

O texto proposto pela British Medical Association em I997 dá ênfase à autonomia do paciente, admite o aborto, desde que permitido em lei e praticado dentro de princípios éticos, e inclui o consentimento esclarecido do paciente para a sua participação em qualquer investigação científica (Gersten Institute, s.d.).

O último documento citado, a Carta do Profissionalismo Médico, não se destina a substituir o juramento de Hipócrates; é, antes, um verdadeiro código de conduta do médico. Foi elaborado em conjunto por diversas instituições médicas norte-americanas e a Federação Europeia de Medicina Interna, tendo sido divulgado em fevereiro de 2002 simultaneamente nas revistas Lancet e Annals of Internal Medicine. Compõe-se de três princípios e dez compromissos, que se acham resumidos nos seguintes itens:

\section{Princípios}

I. Prioridade ao bem-estar do paciente

2. Autonomia do paciente

3. Justiça social

\section{Compromissos}

I. Competência profissional

2. Sinceridade com os pacientes

3. Sigilo profissional

4. Apropriado relacionamento com os pacientes

5. Qualidade do atendimento

6. Facilidade de acesso aos cuidados médicos 
7. Distribuição justa de recursos financeiros alocados à saúde

8. Atualização científica

9. Integridade nos conflitos de interesse

ıо. Responsabilidade profissional

A pergunta que se impõe é: deve o juramento de Hipócrates ser modificado ou substituído por outro documento?

Em I984 foi feita uma pesquisa na classe médica brasileira, por amostragem, sobre se o juramento de Hipócrates deveria ou não ser modificado (Rodrigues, I984). O resultado foi o seguinte:

$\begin{array}{lc}\text { Deve permanecer inalterado } & 80 \% \\ \text { Deve ser modificado } & \text { I } 5 \% \\ \text { Deve ser ignorado } & 5 \%\end{array}$

Também pensamos como a maioria. Julgamos que o juramento de Hipócrates não deve ser "atualizado" nem "modernizado", e sim complementado por outros instrumentos hábeis, como declarações, regulamentos e códigos de Deontologia Médica.

Vimos que atualmente se dá preferência à versão simplificada do juramento que não desce a normas específicas, porém mantém, em linhas gerais, o espírito que presidiu a sua criação e os fundamentos da ética médica, o que o torna válido em qualquer época. Atualizá-lo seria violentá-lo. O juramento de Hipócrates é uma obra de arte e sabedoria, só comparável às mais altas criações da espírito humano e, por isso mesmo, deve ser considerado patrimônio da humanidade e permanecer intocável, como um marco na história da medicina.

\section{Referências Bibliográficas}

Adams, F. The Genuine Works of Hippocrates. (Harvard Classics, vol. 38 ) Boston, P. F. Collier \& Son, I9 Iо.

Annals of Internal Medicine. "Medical Profissionalism in the New Milenium: A Physician Charter". I36, pp. 243-246, 2002.

Bernardes de Oliveira, A. A Evolução da Medicina até o Início do Século xx. São Paulo, Livraria Pioneira Editora, I98 I. 
"O Juramento de Hipócrates”. Anais Paulistas de Medicina e Cirurgia, IOI, pp. 32 I-338, I974.

Carpenter, J. \& Mangin-Lazarus, C. (eds.) Retrouver la médecine. Paris, Synthélabo, I996.

Castiglioni, A. Histoire de la médecine. Paris, Payot, I93 I.

Daremberg, C. Oeuvres Choisies d'Hippocrate. Apud Lopes, O. C. A Medicina no Tempo. São Paulo, Melhoramentos, I969.

Edelstein, L. Ancient Medicine. Baltimore, The Johns Hopkins University Press, I 987 .

Gersten Institute. “The Modern Oath of Hippocrates”. Disponível em http://www. imagerynet.com/hippo.ama.html, acesso em 3 nov. 2002.

Hipócrates. Hippocrate: Oeuvres complètes, vol. 2. Trad. de E. Littré. Paris, Javal et Bourdeaux, I932, p. 3.

. Hippocrates, vol. I. (The Loeb Classical Library) Trad. de W. H. S. Jones. Cambridge, Harvard University Press, I972, pp 298-30I.

Marketos, S.G. (ed.). Proceedings of the First International Medical Olympiad. Atenas, International Hippocratic Foundation of Kos, I996, p. 60.

New York Medical College. Student handbook. Disponível em http://www.nymc.edu/ Medical/handbook/chap I 8.asp, acesso em 3 nov. 2002.

Ordre National des Médecins. "Le serment prêté par les jeunes médecins devant l'Ordre”. Disponível em http://www.ordmed.org/commente/serment.html, acesso em 3 nov. 2002.

Rodrigues, L. A. “Juramento de Hipócrates: Que Seja Eterno Enquanto Dure”. Médico Moderno, pp. 26-34, nov.-dez. I984.

Value of Life Committee Inc. “Modern Oath of Hippocrates”. Disponível em http:// www.ttuhsc.edu/pages/students/cmds/oath-mod-hippocrates.html, acesso em 3 nov. 2002.

Vasconcelos, E. “Juramento de Hipócrates”. Revista Paulista de Medicina, 83, pp. I96-204, I974. 